\title{
Depression and Obsessive-Compulsive Disorders Amid the COVID-19 Pandemic in Saudi Arabia
}

Noara AlHusseini ${ }^{1}$, Muhammad Sajid ${ }^{2}$, Afaf Altayeb ${ }^{3}$, Shahd Alyousof ${ }^{4}$, Haifa Alsheikh ${ }^{3}$, Abdulrahman Alqahtani $^{1}$, Afrah Alsomali ${ }^{3}$

1. Epidemiology and Public Health, Alfaisal University College of Medicine, Riyadh, SAU 2. Pathology, Alfaisal University College of Medicine, Riyadh, SAU 3. Medicine, Alfaisal University College of Medicine, Riyadh, SAU 4. Public Health Sciences, Alfaisal University College of Medicine, Riyadh, SAU

Corresponding author: Noara AlHusseini, nalhusseini@alfaisal.edu

\begin{abstract}
Introduction: Coronavirus disease 2019 (COVID-19) is a global pandemic with significant morbidity and mortality. The Saudi government adopted mandatory home quarantine and curfew hours for all residents, excluding essential service workers. During the lockdown, the public's fear of infection can adversely impact mental health, causing psychological distress. The objective of this research is to assess frequency of depression and obsessive-compulsive disorder (OCD) among the general population during COVID-19 pandemic in Saudi Arabia.
\end{abstract}

Methodology: This was a cross-sectional study using the Patient Health Questionnaire (PHQ-9) and Obsessive-Compulsive Inventory-Revised assessment test (OCI-R) in Arabic and English languages distributed via social media platforms. Chi-square test was used with significance determined at $\mathrm{p}<0.005$.

Results: We received a total of 2187 responses. Our results showed that being female, single, and unemployed had a higher frequency of suffering from depression whereas higher income levels and higher education was associated with less depression frequency. Increasing age, males, married individuals, higher income groups, higher levels of education and employed individuals were more likely to have OCD during COVID-19 pandemic.

Conclusion: The COVID-19 pandemic period is associated with significant mental health risks among the Saudi population. The results can provide further scientific support to better understand the impact of quarantine on psychological distress and mental health during emergency and disaster situations.

Review began 01/11/2021 Review ended 01/24/2021 Published 01/28/2021

\section{๑) Copyright 2021}

AlHusseini et al. This is an open access article distributed under the terms of the Creative Commons Attribution License CC-BY 4.0., which permits unrestricted use, distribution, and reproduction in any medium, provided the original author and source are credited.
Categories: Psychiatry, Public Health, Epidemiology/Public Health

Keywords: quarantine, covid-19, mental health, depression, obsessive compulsive disorders

\section{Introduction}

Coronavirus disease 2019 (COVID-19) is derived from the coronavirus family. The virus first appeared in China, then continued to spread globally, and was declared a global pandemic by the World Health Organization (WHO) in March 2020 [1,2]. The most common symptoms of COVID-19 include fever, dry cough, shortness of breath, tiredness, headaches, nasal congestion, sore throat, diarrhea, and altered taste and smell sensations [2,3]. To minimize the virus transmission in Saudi Arabia, the government advised social distancing, implemented self-isolation for those affected, and adopted mandatory home-quarantine (lockdown) for all residents [4]. Public health measures to combat the virus's spread impacted daily activities, affecting jobs and causing financial insecurities. The lockdown situation is likely to have an adverse impact on mental health and wellbeing, leading to disruption in people's daily routines [4-6]. Lockdown and quarantine can increase psychological distress leading to conditions such as anxiety, panic attacks, depression, post-traumatic stress disorder (PTSD), and obsessive-compulsive disorder (OCD) [4-6].

Depression is a mood disorder affecting different aspects of a person's life causing a decline in social and occupational functioning. It can also cause physical problems and decrease the person's ability to function in routine activities [7]. The severity of symptoms varies, from feelings of sadness to anxiety or restlessness, loss of interest, sleep disturbances, reduced appetite, and fatigue [8]. Social isolation and distancing can disrupt routines and create fear and anxiety, especially among those with mental health problems [4].

Obsessive-compulsive disorder is unwanted recurring obsessions (thoughts) and compulsions (behaviors) interfering with a person's daily tasks. Some of the common obsessions include fear of germs and wanting things in a symmetrical and orderly manner [9]. Compulsions include excessive cleaning and hand washing, constant checking and rechecking, and arranging things in a specific and precise way. The most common practice of OCD is fear of contamination [10]. OCD symptoms vary between individuals. However, people with OCD cannot control thoughts or behaviors and do not enjoy themselves, which affects daily living [9]. Nonetheless, recommended behaviors that prevent the spread of COVID-19, such as repeated hand washing, 
resemble some compulsive behaviors of OCD [10]. A study showed that OCD symptoms could worsen, as shown in a case of a patient who was previously in remission of OCD but relapsed with the spread of coronavirus [11].

The effect of COVID-19 lockdowns on mental illness frequency needs to be assessed to understand whether the lockdown will alter mental wellbeing in healthy individuals [12]. There is a lack of published data addressing the psychological impact of COVID-19, unlike severe acute respiratory syndrome (SARS) and Middle East respiratory syndrome (MERS) [12], which showed that one of the consequences is increased psychiatric morbidity, ranging from fear and PTSD to depression and anxiety [13-15]. Some recent studies have shown similar psychological distress patterns to SARS and MERS [16]. This study aimed to assess the frequency of depression and OCD among the general population in Saudi Arabia during the COVID-19 pandemic.

\section{Materials And Methods}

The study targeted adults 18 years of age and above living in Saudi Arabia. With an estimated Saudi population of 33.7 million in 2020, the sample size was 384 with a $95 \%$ confidence level. Ethical approval was taken from Alfaisal University Institutional Review Board (IRB) (\#20042), and all ethical requirements of the IRB were fulfilled during this study.

The study was performed in the time of COVID-19 pandemic lockdowns. Therefore, no paper questionnaire was used, instead, only online surveys were distributed through social media platforms such as WhatsApp, Twitter, Instagram, Facebook, and LinkedIn. The questionnaire was made via Google Forms and was written in English and Arabic. Participation was voluntary and anonymous to ensure confidentiality and anonymity, completion of the questionnaire was construed as consent, and finally, access to the responses was limited to the authors only.

The questionnaire consisted of three main sections; first, demographic information such as age, gender, nationality, marital status, level of education, and employment status. Second, the Patient Health Questionnaire (PHQ-9) and finally, Obsessive-Compulsive Inventory-Revised (OCI-R) assessment test [1719]. An Arabic language expert performed face validity for the Arabic version of the questionnaire.

The PHQ-9, also known as Patient Depression Questionnaire, is a quick tool to assess depression among participants. The questionnaire is designed to cover social, occupational, or other important functioning areas $[17,18]$. The questionnaire is included in Appendix 1. The individual responses are calculated and interpreted as a total score as follows: 1-4 no or minimal depression, 5-9 mild depression, 10-14 moderate depression, 15-19 moderately severe depression, and 20-27 severe depression.

The OCI-R is a short version of the OCD assessment survey for assessing symptoms of OCD [19]. It consists of 18 questions that a person answers on a 5-point Likert scale. Scores are generated by adding the individual item scores. The possible range of scores is $0-72$. Mean score for persons with OCD is 28.0 ( $\mathrm{SD}=13.53$ ). The recommended cutoff score is 21 , with scores at or above this level indicating the likely presence of OCD [20]. We analyzed the data via the jamovi project statistics analysis package (Sydney, Australia). Primary data points included age, gender, occupation, and socioeconomic levels. The Chi-square test was employed on categorical variables to examine associations. We determined significance when the p-value was $<0.05$.

\section{Results}

We analyzed a total of 2186 responses. The socio-demographic characteristics of the respondents are shown in Table 1.

\begin{tabular}{|c|c|c|}
\hline $\mathrm{N}=2186$ & $\mathbf{n}$ & $\%$ \\
\hline \multicolumn{3}{|c|}{ Age Group (years) } \\
\hline 18-24 & 484 & $22.1 \%$ \\
\hline $25-35$ & 620 & $28.4 \%$ \\
\hline $36-45$ & 479 & $21.9 \%$ \\
\hline $46-55$ & 348 & $15.9 \%$ \\
\hline$>55$ & 255 & $11.7 \%$ \\
\hline \multicolumn{3}{|l|}{ Gender } \\
\hline Male & 864 & $39.5 \%$ \\
\hline Female & 1322 & $60.5 \%$ \\
\hline
\end{tabular}




\section{Cureus}

Nationality

Non-Saudi

Marital status

Single

Married

Divorced

98

Monthly income (SR)

9,999 or less

$10,000-19,999$

20,000 or more

Prefer not to answe

Level of education

High school, diploma or less

Bachelor's degree

Graduate degree

Employment status

Employed

Unemployed

Employment type

Healthcare

Food industry, Supermarket, Delivery

Military force, Policemen

How many times did you leave your home in last one week

1-2 times/week

3-4 times/week

5-7 times/week

Diagnosed or direct contact with COVID19 case

Yes, I have been diagnosed with No direct contact with a case

Yes, I have been diagnosed with direct contact with a confirmed case

No, I have not been diagnosed with No direct contact with a case

No, I have not been diagnosed, but I had direct contact with a confirmed case

Depression calculated using the Patient Health Questionnaire (PHQ-9) 


\section{Cureus}

Moderately Severe Depression

Severe Depression

OCD (OCl-R)

Most likely has OCD

Most likely does not have OCD

\section{TABLE 1: Demographics of Respondents ( $\mathrm{N}=\mathbf{2 1 8 6})$}

OCI-R: obsessive-compulsive inventory-revised assessment test

The results showed that $65.2 \%$ of the respondents had depression and $62.4 \%$ most likely had OCD. Analysis of categorical variables in relation to depression and OCD are shown in Table 2 and Table 3, respectively. 


\section{Cureus}

\begin{tabular}{|c|c|c|c|c|c|c|c|c|c|c|c|}
\hline $\begin{array}{l}\text { Depression } \\
\text { Age (years) }\end{array}$ & \multicolumn{2}{|c|}{$\begin{array}{l}\text { Minimal } \\
\text { Depression }\end{array}$} & \multicolumn{2}{|c|}{$\begin{array}{l}\text { Mild } \\
\text { Depression }\end{array}$} & \multicolumn{2}{|c|}{$\begin{array}{l}\text { Moderate } \\
\text { Depression }\end{array}$} & \multicolumn{2}{|c|}{$\begin{array}{l}\text { Moderately Severe } \\
\text { Depression }\end{array}$} & \multicolumn{2}{|c|}{$\begin{array}{l}\text { Severe } \\
\text { Depression }\end{array}$} & $\begin{array}{l}\text { P-value Chi- } \\
\text { square test }\end{array}$ \\
\hline $18-24$ & 86 & $17.8 \%$ & 139 & $28.7 \%$ & 119 & $24.6 \%$ & 105 & 21.7 & 35 & 7.2 & \multirow{5}{*}{$<.001$} \\
\hline $25-35$ & 160 & $25.8 \%$ & 189 & $30.5 \%$ & 140 & $22.6 \%$ & 93 & $15.0 \%$ & 38 & 6.1 & \\
\hline $36-45$ & 166 & $34.7 \%$ & 180 & $37.6 \%$ & 82 & $17.1 \%$ & 42 & $8.8 \%$ & 9 & $1.9 \%$ & \\
\hline $46-55$ & 178 & $51.1 \%$ & 98 & $28.2 \%$ & 53 & $15.2 \%$ & 11 & $3.2 \%$ & 8 & $2.3 \%$ & \\
\hline $55+$ & 171 & $67.1 \%$ & 61 & $23.9 \%$ & 13 & $5.1 \%$ & 10 & $3.9 \%$ & 0 & $0.0 \%$ & \\
\hline \multicolumn{12}{|l|}{ Gender } \\
\hline Male & 387 & $44.8 \%$ & 251 & $29.1 \%$ & 132 & $15.3 \%$ & 65 & $7.5 \%$ & 29 & $3.4 \%$ & \multirow{2}{*}{$<.001$} \\
\hline Female & 374 & $28.3 \%$ & 416 & $31.5 \%$ & 275 & $20.8 \%$ & 196 & $14.8 \%$ & 61 & $4.6 \%$ & \\
\hline \multicolumn{12}{|l|}{ Nationality } \\
\hline Saudi & 674 & $34.9 \%$ & 590 & $30.6 \%$ & 355 & $18.4 \%$ & 231 & $12.0 \%$ & 80 & $4.1 \%$ & \multirow{2}{*}{.967} \\
\hline Non-Saudi & 87 & $34.0 \%$ & 77 & $30.1 \%$ & 52 & $20.3 \%$ & 30 & $11.7 \%$ & 10 & $3.9 \%$ & \\
\hline \multicolumn{12}{|l|}{ Marital Status } \\
\hline Single & 169 & $20.3 \%$ & 232 & $27.8 \%$ & 210 & $25.2 \%$ & 171 & $20.5 \%$ & 52 & $6.2 \%$ & \\
\hline Married & 545 & $44.2 \%$ & 396 & $33.1 \%$ & 182 & $18.4 \%$ & 79 & $6.4 \%$ & 31 & $2.5 \%$ & \\
\hline Divorced & 32 & $32.7 \%$ & 35 & $35.7 \%$ & 14 & $14.3 \%$ & 10 & $10.2 \%$ & 7 & $7.1 \%$ & \\
\hline Widowed & 15 & $71.4 \%$ & 4 & $19.0 \%$ & 1 & $4.8 \%$ & 1 & $4.8 \%$ & 0 & $0.0 \%$ & \\
\hline \multicolumn{12}{|l|}{ Monthly Income } \\
\hline 0 to 9,999 SAR & 152 & $27.0 \%$ & 161 & $28.6 \%$ & 126 & $22.4 \%$ & 93 & $16.5 \%$ & 31 & $5.5 \%$ & \multirow{4}{*}{$<.001$} \\
\hline 10,000 to 19,999 SAR & 186 & $34.6 \%$ & 165 & $30.7 \%$ & 117 & $21.7 \%$ & 49 & $9.1 \%$ & 21 & $3.9 \%$ & \\
\hline 20,000 SAR or more & 224 & $46.6 \%$ & 157 & $32.6 \%$ & 67 & $13.9 \%$ & 25 & $5.2 \%$ & 8 & $1.7 \%$ & \\
\hline Prefer not to say & 199 & $32.9 \%$ & 184 & $30.5 \%$ & 97 & $16.1 \%$ & 94 & $15.6 \%$ & 30 & $5.0 \%$ & \\
\hline \multicolumn{12}{|l|}{ Education } \\
\hline $\begin{array}{l}\text { high school, Diploma } \\
\text { or less }\end{array}$ & 172 & $30.6 \%$ & 156 & $27.7 \%$ & 111 & $19.7 \%$ & 94 & $16.7 \%$ & 30 & $5.3 \%$ & \multirow{3}{*}{$<.001$} \\
\hline Bachelor's degree & 409 & $34.3 \%$ & 391 & $32.8 \%$ & 212 & $17.8 \%$ & 130 & $10.9 \%$ & 49 & $4.1 \%$ & \\
\hline Graduate degree & 180 & $41.7 \%$ & 120 & $27.8 \%$ & 84 & $19.4 \%$ & 37 & $8.6 \%$ & 11 & $2.5 \%$ & \\
\hline \multicolumn{12}{|l|}{ Employment } \\
\hline Employed & 446 & $36.4 \%$ & 403 & $32.9 \%$ & 222 & $18.1 \%$ & 117 & $9.6 \%$ & 37 & $3 \%$ & \multirow{2}{*}{$<.001>$} \\
\hline Unemployed & 315 & $32.8 \%$ & 264 & $27.5 \%$ & 185 & $19.3 \%$ & 144 & $15 \%$ & 5 & $5.5 \%$ & \\
\hline
\end{tabular}

TABLE 2: Chi-square test for Depression and Demographics 


\section{Cureus}

\begin{tabular}{|c|c|c|c|}
\hline \multirow[t]{2}{*}{ OCD } & \multicolumn{2}{|c|}{ Most likely has OCD } & \multirow[t]{2}{*}{ P-value } \\
\hline & $\mathrm{N}$ & $\%$ & \\
\hline \multicolumn{4}{|l|}{ Age } \\
\hline $18-24$ & 233 & 48.1 & \multirow{5}{*}{$<0.001$} \\
\hline $25-35$ & 355 & 57.3 & \\
\hline $36-45$ & 320 & 66.8 & \\
\hline $46-55$ & 250 & 71.8 & \\
\hline $55+$ & 207 & 81.2 & \\
\hline \multicolumn{4}{|l|}{ Gender } \\
\hline Male & 582 & 67.4 & \multirow{2}{*}{$<0.001$} \\
\hline Female & 783 & 59.2 & \\
\hline \multicolumn{4}{|l|}{ Marital Status } \\
\hline Single & 425 & 51 & \multirow{4}{*}{$<0.001$} \\
\hline Married & 861 & 69.8 & \\
\hline Divorced & 66 & 67.3 & \\
\hline Widowed & 13 & 61.9 & \\
\hline \multicolumn{4}{|l|}{ Monthly Income } \\
\hline 0 to 9,999 SAR & 320 & 56.8 & \multirow{4}{*}{$<0.001$} \\
\hline 10,000 to 19,999 SAR & 347 & 64.5 & \\
\hline 20,000 SAR or more & 354 & 73.6 & \\
\hline Preferer not to say & 344 & 57 & \\
\hline \multicolumn{4}{|l|}{ Education } \\
\hline High school, Diploma or less & 309 & 54.9 & \multirow{3}{*}{$<0.001$} \\
\hline Bachelor's degree & 772 & 64.8 & \\
\hline Graduate degree & 284 & 65.7 & \\
\hline \multicolumn{4}{|l|}{ Employment } \\
\hline Employed & 798 & 65.1 & \multirow{2}{*}{0.003} \\
\hline Unemployed & 567 & 59 & \\
\hline
\end{tabular}

TABLE 3: Chi-square test for OCD and demographics

The frequency of moderate to severe depression was more in females (40\%) as compared to males (26\%) $(p<0.001)$. The frequency of severe depression was highest among the youngest age group $18-24$ years $(7.2 \%)$ $(\mathrm{p}<0.01)$. Single individuals $(52 \%)$ were more likely to be suffering from moderate to severe depression as compared to married respondents $(27 \%)(p<0.01)$. Unemployed individuals $(40 \%)$ were more likely to be moderately to severely depressed as compared to employed (31\%). Respondents with higher income and higher educational levels were less likely to be suffering from depression (Table 2).

Increasing age increased the frequency of having $\mathrm{OCD}$ as depression was more frequent in the age group 55 years or older $(81.2 \%)$ as compared to the age group 18-24 years old $(48.1 \%)(\mathrm{p}<0.01)$. Males showed more frequency of OCD (67.4\%) than females $(59.2 \%)(\mathrm{p}<0.01)$. Moreover, married individuals and higher income groups showed a higher incidence of OCD. Higher education levels and employed individuals were more likely to have OCD (Table 3). 


\section{Discussion}

Correlations have been drawn in the literature between previous pandemics and increased psychological distress [21]. We therefore have attempted to assess the frequencies of depression and OCD in the general population of Saudi Arabia during the COVID-19 pandemic.

The results showed that $65.2 \%$ of the respondents had depression and that females are more likely to develop moderate to severe depression during COVID-19 than males. This result agrees with a study conducted in China, with females showing higher psychological distress than males [6]. In addition, local studies have shown that females were at higher risk of developing psychological distress and depressive symptoms [21]. The high risk among females could be due to gender-related hormonal differences in response to stress [21]. Contrary to our findings, a study in China concluded no statistically significant difference between genders among the general Chinese population regarding depression associated with the COVID-19 pandemic [22]. Our results also showed that married individuals are less likely to suffer from severe depression than single individuals. In contrast, Lades et al. (2020) have reported less emotional wellbeing among married individuals, which could be associated with adjusting household difficulties during the quarantine [23]. Across age groups, our study indicates that the older population is less likely to develop depression compared to the younger population. Related evidence was reported from China as younger participants (<35 years) were more likely to develop depression during the COVID-19 pandemic than their older counterparts ( $\geqslant 35$ years). A Chinese student living in Saudi Arabia committed suicide after being quarantined due to suspicions of being infected by COVID-19 virus. However, the first suicide case related to COVID-19 was reported in India in February 2020; a 50-year-old man misdiagnosed with COVID-19 committed suicide after reading mortality rates in the media [24]. Younger people spend more time on social media, which can mislead and influence their knowledge and judgement by unreliable information regarding COVID-19, causing significant panic and depression [21]. Social media is associated with negative effect on emotional wellbeing [23]. Also, the younger population is generally more involved in outdoor activities than the older age group [21], which was documented to enhance emotional wellbeing [23]. Thus, as a result of strict quarantine and lockdown measurements, daily activities have been dramatically curtailed [25]. Those reasons can justify our results of the highest frequency of severe depression among the youngest age group 18-24 years. During the pandemic, high unemployment rate was notable, which is associated with many unfavorable psychological outcomes, including increased anxiety and fear about future opportunities and career options [26]. Our study showed that individuals with lower socioeconomic status and those unemployed were more likely to be moderately to severely depressed. Furthermore, the economic downturn in certain countries led to widespread unemployment, which threatened workers' job security across different sectors, leading to mental distress [26]. When comparing educational levels, we observed that respondents with higher education are less likely to be depressed. While no statistically significant correlation was found in our study between depression and different nationalities, a study in China revealed that migrant workers had higher levels of distress [6].

Regarding OCD, our results showed that $62.4 \%$ most likely had OCD. Although OCD causes remain unexplained, there is a high prevalence among both genders. However, males are more likely to develop OCD during COVID-19 than females. Likewise, in a recent Canadian study, males were found to have more obsessive and compulsive symptoms [27]. We also found that married participants are most likely to have OCD. Another study had similar results in which single people were less likely to have obsessive symptoms [27]. Our results show that the older population is more likely to develop OCD. Additionally, our study found that OCD was most likely to occur as age increased, which is in concordance with the study conducted in Canada $(\mathrm{p}<0.01)$ [27]. The elderly population is at higher risk of developing complications [28]. Thus, they are more likely to adhere to the public health recommendations such as repeatedly washing hands to avoid the complications. Additionally, our study showed that employed people were more likely to suffer from OCD, which was also reported by the Canadian study [27]. However, respondents with high educational levels are more likely to develop OCD than those with lower education levels, as noted significantly in other studies [27]. No statistically significant correlation was found between OCD and different nationalities. However, Caucasians were more likely to suffer from obsessive and compulsive symptoms than Asians and other ethnicities in Canada [27]. The absence of associations in our study might be due to the small number of non-Saudi participants.

Our findings highlight that public health officials must increase their focus on raising awareness about mental health, especially during a pandemic. Increasing the awareness will help in limiting the stigma around this issue [29]. Some studies have shown that physical activity has positive effects for those with depression and OCD so it is important to highlight the importance of being physically active among those who suffer from depression and OCD [30].

One limitation of this study is selection bias, since only participants with access to social media platforms were able to participate. Also, this is a cross-sectional study, which means no causal relationship could be established. The questionnaire was self-administered, which may have caused recall bias. The response rate was higher than expected and it could be due to lockdown measures. The questions in the survey do not provide actual diagnosis of depression or OCD, it only provides initial assessment. However, since coronavirus is recent, this study adds a lot of value to the current literature since no studies have focused on both depression and OCD amid COVID-19 among the Saudi population, which eliminates publication bias. 
Future studies are needed to better understand mental health during lockdown.

\section{Conclusions}

The COVID-19 pandemic period is associated with significant mental health risks among the Saudi population. Females, younger population, single individuals, low socioeconomics, and low education level groups were found to be more likely to develop depression. Furthermore, males, older population, married individuals, low socioeconomics, unemployed, and high education level groups were at a higher risk for developing OCD. The results can provide further scientific support to better understand the impact of quarantine on psychological distress and mental health during emergency and disaster situations.

\section{Additional Information}

\section{Disclosures}

Human subjects: Consent was obtained or waived by all participants in this study. Alfaisal University issued approval 20042. Animal subjects: All authors have confirmed that this study did not involve animal subjects or tissue. Conflicts of interest: In compliance with the ICMJE uniform disclosure form, all authors declare the following: Payment/services info: All authors have declared that no financial support was received from any organization for the submitted work. Financial relationships: All authors have declared that they have no financial relationships at present or within the previous three years with any organizations that might have an interest in the submitted work. Other relationships: All authors have declared that there are no other relationships or activities that could appear to have influenced the submitted work.

\section{References}

1. Fauci AS, Lane HC, Redfield RR: COVID-19 - navigating the uncharted . N Engl J Med. 2020, 382:1268-9. 10.1056/NEJMe2002387

2. Hassan SA, Sheikh FN, Jamal S, Ezeh JK, Akhtar A: Coronavirus (COVID- 19): a review of clinical features, diagnosis, and treatment. Cureus. 2020, 12:e7355. 10.7759/cureus.7355

3. Pan L, Mu M, Yang P, et al.: Clinical characteristics of COVID-19 patients with digestive symptoms in Hubei, China: a descriptive, cross-sectional, multicenter study. Am J Gastroenterol. 2020, 115:766-773. 10.14309/ajg.0000000000000620

4. Alyami M, Henning M, Krägeloh CU, Alyami H: Psychometric evaluation of the Arabic version of the Fear of COVID-19 Scale. Int J Ment Health Addict. 2020, 1-14. 10.1007/s11469-020-00316-X

5. Joseph R, Alshayban D, Lucca J, Alshehry Y: The immediate psychological response of the general population in Saudi Arabia during COVID-19 pandemic: a cross-sectional study. medRxiv. 2020, 10.1101/2020.06.19.20135533

6. Qiu J, Shen B, Zhao M, Wang Z, Xie B, Xu Y: A nationwide survey of psychological distress among Chinese people in the COVID-19 epidemic: implications and policy recommendations. Gen Psychiatr. 2020, 33:e100213. 10.1136/gpsych-2020-100213

7. Depression. (2018). Accessed: 2020: https://www.nimh.nih.gov/health/topics/depression/index.shtml.

8. Rahim T, Rashid R: Comparison of depression symptoms between primary depression and secondary-toschizophrenia depression. Int J Psychiatry Clin Pract. 2017, 21:314-317. 10.1080/13651501.2017.1324036

9. Obsessive-Compulsive Disorder. (2019). Accessed: 2020: https://www.nimh.nih.gov/health/topics/obsessive-compulsive-disorder-ocd/index.shtml.

10. Rajkumar RP: Contamination and infection: what the coronavirus pandemic could reveal about the evolutionary origins of obsessive-compulsive disorder. Psychiatry Res. 2020, 289:113062. 10.1016/j.psychres.2020.113062

11. Kumar A, Somani A: Dealing with corona virus anxiety and OCD . Asian J Psychiatr. 2020, 51:102053. 10.1016/j.ajp.2020.102053

12. Kaufman KR, Petkova E, Bhui KS, Schulze TG: A global needs assessment in times of a global crisis: world psychiatry response to the COVID-19 pandemic. BJPsych Open. 2020, 6:e48. 10.1192/bjo.2020.25

13. Hawryluck L, Gold WL, Robinson S, Pogorski S, Galea S, Styra R: SARS control and psychological effects of quarantine, Toronto, Canada. Emerg Infect Dis. 2004, 10:1206-12. 10.3201/eid1007.030703

14. Jeong H, Yim HW, Song YJ, Ki M, Min JA, Cho J, Chae JH: Mental health status of people isolated due to Middle East Respiratory Syndrome. Epidemiol Health. 2016, 38:e2016048. 10.4178/epih.e2016048

15. Peng EY, Lee MB, Tsai ST, et al.: Population-based post-crisis psychological distress: an example from the SARS outbreak in Taiwan. J Formos Med Assoc. 2010, 109:524-532. 10.1016/s0929-6646(10)60087-3

16. Zandifar A, Badrfam R: Iranian mental health during the COVID-19 epidemic . Asian J Psychiatr. 2020, 51:101990. 10.1016/j.ajp.2020.101990

17. Al-Qadhi W, ur Rahman S, Ferwana MS, Abdulmajeed IA: Adult depression screening in Saudi primary care: prevalence, instrument and cost. BMC Psychiatry. 2014, 14:190. 10.1186/1471-244X-14-190

18. AlHadi AN, AlAteeq DA, Al-Sharif E, et al.: An arabic translation, reliability, and validation of Patient Health Questionnaire in a Saudi sample. Ann Gen Psychiatry. 2017, 16:32. 10.1186/s12991-017-0155-1

19. Foa EB, Kozak MJ, Salkovskis PM, Coles ME, Amir N: The validation of a new obsessive-compulsive disorder scale: The Obsessive-Compulsive Inventory. Psychol Assess. 1998, 10:206-214. 10.1037/1040-3590.10.3.206

20. Foa EB, Huppert JD, Leiberg S, Langner R, Kichic R, Hajcak G, Salkovskis PM: The Obsessive-Compulsive Inventory: development and validation of a short version. Psychol Assess. 2002, 14:485-96. 10.1037/10403590.14.4.485

21. Al-Hanawi MK, Mwale ML, Alshareef N, Qattan AM, Angawi K, Almubark R, Alsharqi O: Psychological distress amongst health workers and the general public during the COVID-19 pandemic in Saudi Arabia. 


\section{Cureus}

Risk Manag Healthc Policy. 2020, 13:733-742. 10.2147/RMHP.S264037

22. Huang Y, Zhao N: Generalized anxiety disorder, depressive symptoms and sleep quality during COVID-19 outbreak in China: a web-based cross-sectional survey. Psychiatry Res. 2020, 288:112954.

10.1016/j.psychres.2020.112954

23. Lades LK, Laffan K, Daly M, Delaney L: Daily emotional well-being during the COVID-19 pandemic. $\mathrm{Br}$ J Health Psychol. 2020, 25:902-911. 10.1111/bjhp.12450

24. Thakur V, Jain A: COVID 2019-suicides: a global psychological pandemic . Brain Behav Immun. 2020, 88:952-953. 10.1016/i.bbi.2020.04.062

25. Usher K, Bhullar N, Jackson D: Life in the pandemic: social isolation and mental health. J Clin Nurs. 2020, 29:2756-2757. 10.1111/jocn.15290

26. Restubog SL, Ocampo AC, Wang L: Taking control amidst the chaos: emotion regulation during the COVID19 pandemic. J Vocat Behav. 2020, 119:103440. 10.1016/j.jvb.2020.103440

27. Abba-Aji A, Li D, Hrabok M, et al.: COVID-19 Pandemic and mental health: prevalence and correlates of new-onset obsessive-compulsive symptoms in a Canadian province. Int J Environ Res Public Health. 2020, 17:6986. 10.3390/ijerph17196986

28. Armitage R, Nellums LB: COVID-19 and the consequences of isolating the elderly . Lancet Public Health. 2020, 5:e256. 10.1016/S2468-2667(20)30061-X

29. Zhou X, Snoswell CL, Harding LE, Bambling M, Edirippulige S, Bai X, Smith AC: The role of telehealth in reducing the mental health burden from COVID-19. Telemed J E Health. 2020, 26:377-379. 10.1089/tmj.2020.0068

30. Fineberg NA, Van Ameringen M, Drummond L, et al.: How to manage obsessive-compulsive disorder (OCD) under COVID-19: a clinician's guide from the International College of Obsessive Compulsive Spectrum Disorders (ICOCS) and the Obsessive-Compulsive and Related Disorders Research Network (OCRN) of the European College of Neuropsychopharmacology. Compr Psychiatry. 2020, 100:152174.

10.1016/j.comppsych.2020.152174 